\title{
Tuberculosis transmission in public locations in Tanzania: a novel approach to studying airborne disease transmission
}

Jerry Hella 1, 2, 3, Carl Morrow 4, Francis Mhimbira 1, 2, 3, Samuel Ginsberg 5, Nakul Chitnis ${ }^{2,3}$, Sebastien Gagneux ${ }^{2,3}$, Beatrice Mutayoba ${ }^{6}$, Robin Wood ${ }^{4}$, Lukas Fenner $1,2,3,7$ *

\section{Author affiliations:}

${ }^{1}$ Ifakara Health Institute, Dar es Salaam, Tanzania

2 Swiss Tropical and Public Health Institute, Basel, Switzerland

3 University of Basel, Basel, Switzerland

${ }^{4}$ Desmond Tutu HIV Centre, University of Cape Town, Cape Town, South Africa

${ }^{5}$ Department of Electrical Engineering, Faculty of Engineering and the Built Environment, University of Cape Town, Cape Town, South Africa

${ }^{6}$ National Tuberculosis and Leprosy Program, Dar es Salaam, Tanzania

${ }^{7}$ Institute of Social and Preventive Medicine, University of Bern, Bern, Switzerland

\section{* Corresponding author:}

Dr. Lukas Fenner

Swiss Tropical and Public Health Institute, Socinstrasse 42, 4002 Basel, Switzerland

Phone: +41316313321 Fax: +41316313520

E-Mail: lukas.fenner@unibas.ch

Running title: Tuberculosis transmission hotspots in Tanzania 
Key words: Tuberculosis; transmission; airborne transmission; Tanzania; transmission hotspots; $\mathrm{CO}_{2}$; Wells-Riley equation

\section{Abbreviations:}

$\mathrm{Cl} \quad$ Confidence interval

$\mathrm{CO}_{2} \quad$ Carbon dioxide gas

HCF Health Care Facility

Mtb Mycobacterium tuberculosis

PPM Parts per million

SD Standard deviation

TB Tuberculosis

WHO World Health Organization

Meeting at which part of the data were presented: $47^{\text {th }}$ Union World Conference on Lung Health, Liverpool, UK, 26-29 October 2016.

Declaration of interest: All authors none to declare

Word count, inserts and supplementary information:

Abstract 200 words (max. 200), main text 2,248 words, Inserts: 3 figures, 1 table References: 15, Supplementary Information: 3 figures, 1 table 


\section{ABSTRACT}

Objectives - For tuberculosis (TB) transmission to occur, an uninfected individual must inhale the previously infected breath. Our objective was to identify potential TB transmission hotspots in metropolitan city of Dar es Salaam, Tanzania and to model the annual risk of TB transmission in different locations of public importance.

Methods - We collected indoor carbon dioxide $\left(\mathrm{CO}_{2}\right)$ data from markets, prisons, night clubs, public transportation, religious and social halls, and from schools. Study volunteers recorded social contacts at each of the locations. We then estimated the annual risks of TB transmission using a modified Wells-Riley equation for different locations.

Results - The annual risks of TB transmission were highest among prison inmates (41.6\%) and drivers (20.3\%) in public transport. Lower transmission risks were found in central markets ( $4.8 \%$ for traders, but $0.5 \%$ for their customers), passengers on public transport (2.4\%), public schools (4.0\%), nightclubs (1.7\%), religious $(0.13 \%)$, and social halls $(0.12 \%)$.

Conclusion - For the first time in a country representative of sub-Saharan Africa, we modelled the risk of TB transmission in important public locations by using a novel approach of studying airborne transmission. This approach can guide identification of TB transmission hotspots and targeted interventions to reach WHO's ambitious End TB targets. 


\section{BACKGROUND}

One quarter of the world's population is estimated to be infected with Mycobacterium tuberculosis (Mtb). ${ }^{1}$ Transmission of Mtb occurs when uninfected persons inhale infectious droplet nuclei from the infected. ${ }^{2}$ Droplet nuclei with diameters of 1 to $5 \mu \mathrm{m}$ can remain suspended in air for many minutes to hours, ${ }^{3}$ thus making Mtb highly transmissible in overcrowded locations with poor ventilation. For this and other reasons, tuberculosis (TB) remains a major public health problem worldwide.

One way to estimate the risk of TB transmission begins with measuring environmental levels of carbon dioxide $\left(\mathrm{CO}_{2}\right)$ levels. ${ }^{4,5} \mathrm{CO}_{2}$ levels combined with social contact data allow calculation of the volumes of rebreathed air in order to estimate the potential for airborne disease transmission. ${ }^{6} \mathrm{~A}$ modified Wells and Riley equation can be used to estimate TB transmission, taking into account the re-breathed air fraction (estimated from indoor and outdoor $\mathrm{CO}_{2}$ levels), time at risk, the infectious dose (quanta of contagion), and the number of people occupying the confined space. ${ }^{4,6,7}$

Until recently, only studies from Cape Town, South Africa have used this approach. Additional studies in settings more representative of sub-Saharan African countries, which have the highest burden of TB, are needed. We therefore studied potential TB transmission hotspots in metropolitan Dar es Salaam, Tanzania using this novel, $\mathrm{CO}_{2}$-based approach to model the risk of TB transmission as the basis for planning intervention studies. 


\section{METHODS}

\section{Study locations and design}

We used exposure assessment methods in Dar es Salaam where $22 \%$ of 62,952 new TB cases in Tanzania were notified in 2013, making the city a TB hotspot. ${ }^{8}$ Adult volunteers carried $\mathrm{CO}_{2}$ monitors to locations of public importance, and they also recorded the time spent and the number of people at each location. Volunteers collected data between February 2015 and August 2015. We did not include health care facilities (HCF), as waiting rooms are usually open-air in Tanzania and as a study from South Africa indicated that the contribution of HCFs to the annual risk of TB transmission was small with indoor contact accounting only $0.5 \%$ of all contacts. ${ }^{9}$ We obtained written permission from the Ministry of Health and Social Welfare through the National Tuberculosis and Leprosy Program to collect the infrastructure-related $\mathrm{CO}_{2}$ data at public locations. In addition, the Ministry of Home Affairs (Tanzania Prisons) issued permission to enter prisons for data collection.

Market. The largest market in Dar es Salaam, known as Kariakoo, has an underground floor, which is populated daily by $100-180$ people during each hour of the day. Most retail traders elsewhere in Dar es Salaam make wholesale purchases of agricultural products from this market.

Prisons. The two largest facilities in the Dar es Salaam region with over 1,000 inmates were included. One prison is a short-term facility for the temporarily remanded who awaits court rulings, while the other is a long-term correctional facility. While inmates are outdoors during the day, at night they share cells that are occupied by approximately 40 inmates. Prison guards placed the monitors in different cells during the night to collect $\mathrm{CO}_{2}$ data in the facilities.

Night clubs. We collected data from eight of the largest popular nightclubs in the city 
that prohibit indoor cigarette smoking. The night clubs were sound proof and relied upon alternative ventilation mechanisms such as closed air conditioning systems.

Public transportation. Public transportation in Dar es Salaam largely relies upon two commuter bus designs with carrying capacities of 15 to 22 and 32 to 40 passengers.

Religious and social halls. Religious halls consist of mosques and churches with open ventilation complemented by fans for cooling. Social halls, in contrast, have closed ventilation systems that rely on air conditioning, and they are used for family events such as wedding receptions.

Schools. We collected data from colleges and schools (day and boarding schools) in Dar es Salaam. The schools typically have open windows and no other type of ventilation. The classrooms hold 40 to 50 students in each room.

\section{Data collection, definitions and statistical analysis}

We collected social contact data using standardized data collection forms (number of people and time at each location) and environmental $\mathrm{CO}_{2}$ data from the monitors used in previous studies elsewhere..$^{4,5,7}$ The workflow for data collection is presented in Supplementary Figure 1. Volumes of rebreathed air were calculated based on indoor and outdoor $\mathrm{CO}_{2}$ levels at specific times, and accounted for the number of people present and assumed a respiration rate of eight breaths per minute..$^{4,5,10}$ All analyses were performed in Stata software version 13.1 (Stata Corp; Texas, USA).

TB transmission risk was defined as the probability of an individual acquiring a primary infection that would result in formation of a Ghon complex in the lungs. Annual risk of transmission was defined as the probability of an individual acquiring a primary tuberculous infection in one year in a given location. We defined quantum as the number of infectious droplet required to infect $63.2 \%$ (i.e., $1-e^{-1}$ ) of susceptible 
individuals in a indoor environment. ${ }^{11}$

The calculation of shared rebreathed air (either as liter/minute or liter/hour) was based on environmental $\mathrm{CO}_{2}$ data and the number of people present at a given location. ${ }^{5,10}$ We studied the time spent at different locations with poor ventilation $\left(\mathrm{CO}_{2}\right.$ level $\geq 1,000$ parts per million). ${ }^{7,10}$ For continuous variables, we used the unpaired Student's $t$-test (two sided).

\section{Modelling the annual risk of TB transmission}

We used the modified Wells-Riley considering the work of Rudnick Milton on nonsteady state situations to estimate the annual risk of TB transmission. ${ }^{4,6,7}$ We parameterized the Equations 1 (a-c) based on previously published assumptions ${ }^{5,7}$ and based on data collected in this study (Supplementary Table 1). The annual risk $(A R)$ of transmission was calculated as function of the time spent per year at a given location. We used 38,000 parts per million as the $\mathrm{CO}_{2}$ levels in exhaled breaths $\left(\mathrm{CO}_{2}\right.$ breathed out). ${ }^{5,7}$ Briefly, we calculated the risk of TB transmission at each time $(P)$ by using equation $1 \mathrm{a}$ :

$P=1-e^{\left(\frac{-f l q t}{n}\right)}$

Equation: 1a

Where rebreathed fraction, $f=\frac{\text { CO2 indoor }- \text { CO2 outdoor }}{\text { CO2 breathed out }}$

$P$, probability of TB transmission; $f$, rebreathed fraction; $I$, number of infectious individuals in space; $q$, rate of generation of infectious quanta; $t$, duration of exposure; $n$, total number of contacts met by one infectious person. ${ }^{4,6,7}$

Then we calculated the annual exposure time $(T)$ at each location using equation $1 \mathrm{~b}$ : 
$T=\sum_{a} C_{a} t_{a}$

Equation: 1b

Where $\boldsymbol{C}_{\boldsymbol{a}}$, is the annual number of visits at a given location, and $\boldsymbol{t}_{\boldsymbol{a}}$, is the time spent during each visit at a given location. ${ }^{7}$

Finally the annual risk of TB transmission was determined by including the annual time of exposure (1a) in the instantaneous risk of transmission (1b), and is summarized in the final equation:

$A R=1-e^{\left(\frac{-f l q T}{n}\right)}$

Equation: 1c

In summary, the calculation of the risk of transmission risk took into account (i) the time of exposure, (ii) the number of people at risk, (iii) the magnitude of infectious droplet generated, (iv) and the underlying prevalence of TB among people at risk. 


\section{RESULTS}

Prisons had the highest mean $\mathrm{CO}_{2}$ level $1,892 \mathrm{ppm}$, followed by night clubs $(1,488 \mathrm{ppm})$ and social halls $(1,262.9 \mathrm{ppm})$. The lowest mean $\mathrm{CO}_{2}$ levels were recorded in schools and religious halls (655 ppm and 629 ppm, respectively). Summary statistics for $\mathrm{CO}_{2}$ levels in Dar es Salaam's largest market, prisons, nightclubs, public transportation, religious settings and social halls, and schools are further detailed in Table 1.

Risk of TB transmission in the largest market. The mean value (standard deviation) of rebreathed air inside the market was $0.05(0.02) \mathrm{L} / \mathrm{min}$. At mean $\mathrm{CO}_{2}$ levels of 730 ppm, the annual risk of TB transmission for a trader and customer were $4.8 \%$ and $0.5 \%$, respectively (Figure 1 ). The mean annual risk of TB transmission was significantly higher for traders than for customers $(4.9 \%, 95 \%$ confidence interval $[\mathrm{Cl}]$ : 4.77, 5.05\%, vs. 0.49\%, Cl: 0.48, 0.51\%; $P<0.001$; Figure 2 .

Risk of TB transmission in prisons. On average a prisoner rebreathed $0.14(0.1)$ L/min of air from fellow prison inmates at night. A prison inmate rebreathed an average of $65 \mathrm{~L}(95 \% \mathrm{Cl}: 63.8,67.8)$ of air per night from another inmate. At mean $\mathrm{CO}_{2}$ level, the annual risk of TB transmission for a prisoner spending nights in a cell occupied by 40 prison inmates was $41.6 \%$ (Figure 1 ).

Risk of TB transmission in nightclubs. Poor ventilation conditions were observed in $15.8(64.3 \%)$ hours out of 2.5 hours of observation, with a mean rebreathed air value of $0.2 \mathrm{~L} / \mathrm{min}$ (Supplementary Figure 2). The mean rebreathed air was significantly higher during Friday night than Saturday night ( 0.5 vs $0.3 \mathrm{~L} / \mathrm{min}, P<0.001)$. Assuming one infectious case per 100 people, the risk of TB transmission ranged from $0.02 \%$ for 2 hours to $0.03 \%$ for four hours. Assuming one spends four hours per weekend in a 
nightclub and quanta of contagion rate of 1.25 /hour, we estimated the annual risk of TB transmission to be $1.7 \%$ inside a nightclub at a mean $\mathrm{CO}_{2}$ level of $1,488 \mathrm{ppm}$ (Figure 1).

Risk of TB transmission on public transportation. Overall, commuters spent 62.5 (39.5\%) hours of the total time under observation (158 hours) on buses in poorly ventilated conditions. The annual risk of TB transmission for a passenger making 264 bus trips could be up to $2.4 \%$ per year (Figure 1 ). The annual risk for a bus driver or conductor on a bus for 10 hours each day for 264 days was 20.3\% (Figure 3). Overall, the mean annual TB transmission risk for a driver was significantly higher than for a passenger: 20.3 (95\% Cl: 20.0, 20.5\%) vs. 2.36 (95\% Cl: 2.3, 2.4\%; $P<0.001$, Table 1, Figure 3).

Risk of TB transmission at religious and social halls. Overall, mosques and churches were well ventilated, with $\mathrm{CO}_{2}$ levels not exceeding 1,000 ppm. Assuming two hours spent each week in these religious halls, the mean annual risk of TB transmission was only $0.13 \%$. Social halls had a mean $\mathrm{CO}_{2}$ level of $1,262.9$ (149) ppm (Table 1). However, the mean annual risk of TB transmission was only $0.12 \%$ with visits to social halls totaling 32 hours per year (Figure 1).

Risk of TB transmission in schools. We observed ventilation conditions at both day schools and boarding schools (Supplementary Figure 3). The annual risk of TB transmission associated with 1,280 hours spent in a class of 50 students at a mean $\mathrm{CO}_{2}$ level of $655 \mathrm{ppm}$ was estimated to be $4.02 \%$ (Figure 1). 


\section{DISCUSSION}

We found the highest annual risks of TB transmission from an urban setting of Dar es Salaam in prisons (41.6\%), public transportation (20.3\%), schools (4.02\%), and nightclubs $(1.7 \%)$, while risks were lowest in markets $(0.5 \%)$, religious halls $(0.13 \%)$ and social halls (0.12\%). Generally, the annual transmission risk varies by location due to differing times spent in these venues and their (quite varied) ventilation situations. Our quantitative comparison of transmission risks has the potential to reveal why Dar es Salaam is a TB transmission hotspot in Tanzania.

Prisons unquestionably are sites with high risk of TB transmission. We found that the annual TB transmission risk (up to 90\%) was similar to that seen in prisons in South Africa and Brazil. ${ }^{12,13}$ These rates challenge the public health of surrounding communities. The risk of acquiring TB in the short-term correctional facility is approximately eight times higher than that of a trader at the Kariakoo market. The TB transmission risk when visiting nightclubs was comparable to that of a regular passenger in local public transportation in South Africa. ${ }^{7}$ The risks faced by personnel operating these commuter buses in Tanzania are approximately nine times higher compared to passengers taking the same buses, and four times higher compared to traders in the underground market.

At the largest market in Tanzania, we found that the annual risk among traders was ten times higher than that for customers. This market is a hotspot involving a lot of trading activities at the center of metropolitan Dar es Salaam. Due to this profile, we think this market can play a vital role in the control of TB in the country.

In the schools, we observed a lower risk of TB transmission than that seen at schools in Cape Town, South Africa, which has a different environmental profile 
compared to Dar es Salaam ${ }^{10}$ where, due to comparatively higher humidity and temperature, schools rely on open windows and are better ventilated.

This novel approach in the under researched area provides important findings for the control of TB epidemics. ${ }^{5,7}$ This is the first study to systematically estimate TB transmission risk at important public locations using a novel approach. Perhaps the main limitation of this study lies in its collection of social contact data, which was difficult as seen in other settings with low socio-economic status. Furthermore, we did not take into account the role of immunology among susceptible persons at risk of infection and the virulence of Mtb bacilli. Finally, we also assumed that the air was uniformly distributed in a confined space.

Resources used in the campaign against TB are limited and need to be directed where there is maximum pay off. ${ }^{2}$ Our novel approach can guide targeted infection control interventions for National TB Control Programs. This novel approach demonstrates a lower risk of TB transmission are associated with settings with adequate ventilation and a short total time of exposure such as religious and social halls, but a high risk in prisons, public transport and central markets. This study lays the foundation for the next TB transmission studies employing molecular epidemiology techniques or isolation of Mtb from bio-aerosols ${ }^{14,15}$ that will guide interventions to control TB and reach WHO's ambitious End TB targets by 2035. 
ACKNOWLEDGEMENTS

Funding information: This work was supported by the Rudolf Geigy Foundation (Basel, Switzerland); the South African Medical Research Council (MRC) with funds from National Treasury under the Economic Competitiveness and Support Package [grant no. MRC-RFAUFSP-01-2013/CCAMP to CM and RW]; and the Bill \& Melinda Gates Foundation [grant no. OPP1116641, CM and RW]. 


\section{REFERENCES}

1 Houben Rein MGJ, Dodd Peter J. The Global Burden of Latent Tuberculosis Infection: A Re-estimation Using Mathematical Modelling. PLoS Med 2016;13(10):e1002152. Doi: 10.1371/journal.pmed.1002152.

2 Rieder HL. Epidemiologic basis of tuberculosis control. International Union Against Tuberculosis and Lung Disease (IUATLD); 1999.

3 WELLS WF. On air-borne infection: Study II. Droplets and Droplet Nuclei. Am J Epidemiol 1934;20(3):611-8.

4 Andrews Jason R, Morrow Carl, Walensky Rochelle P, Wood Robin. Integrating Social Contact and Environmental Data in Evaluating Tuberculosis Transmission in a South African Township. J Infect Dis 2014:1-7. Doi: 10.1093/infdis/jiu138.

5 Wood Robin, Morrow Carl, Ginsberg Samuel, Piccoli Elizabeth, Kalil Darryl, Sassi Angelina, et al. Quantification of shared air: A Social and environmental determinant of airborne disease transmission. PLoS One 2014;9(9):1-8. Doi: 10.1371/journal.pone.0106622.

6 Rudnick SN, Milton DK. Risk of indoor airborne infection transmission estimated from carbon dioxide concentration. Indoor Air 2003;13(3):237-45.

7 Andrews Jason R, Morrow Carl, Wood Robin. Modeling the role of public transportation in sustaining tuberculosis transmission in South Africa. Am J Epidemiol 2013;177(6):556-61. Doi: 10.1093/aje/kws331.

8 Ministry of Health and Social Welfare. National Tuberculosis and Leprosy 2013 Annual Report. 2014.

9 Wood Robin, Racow Kimberly, Bekker Linda-Gail, Morrow Carl, Middelkoop 
Keren, Mark Daniella, et al. Indoor social networks in a South African township: potential contribution of location to tuberculosis transmission. PLoS One 2012;7(6). Doi: 10.1371/journal.pone.0039246.

10 Richardson Eugene T, Morrow Carl D, Kalil Darryl B, Bekker Linda-Gail, Wood Robin. Shared air: A renewed focus on ventilation for the prevention of tuberculosis transmission. PLoS One 2014;9(5):e96334. Doi: 10.1371/journal.pone.0096334.

11 Beggs Clive B, Shepherd Simon J, Kerr Kevin G. Potential for airborne transmission of infection in the waiting areas of healthcare premises: stochastic analysis using a Monte Carlo model. BMC Infect Dis 2010;10:247. Doi: 10.1186/1471-2334-10-247.

12 Johnstone-Robertson Simon, Lawn SD, Welte A, Bekker LG, Wood R. Tuberculosis in a South African prison-a transmission modelling analysis. S Afr Med J 2011;101(11):809-13. Doi:

10.1016/j.ygyno.2014.12.035.Pharmacologic.

13 Urrego Juliana, Ko Albert I, da Silva Santos Carbone Andrea, Paião Dayse Sanchez Guimarães, Sgarbi Renata Viebrantz Enne, Yeckel Catherine W, et al. The Impact of Ventilation and Early Diagnosis on Tuberculosis Transmission in Brazilian Prisons. Am J Trop Med Hyg 2015;93(4):739-46. Doi: 10.4269/ajtmh.15-0166.

14 Wood Robin, Morrow Carl, Barry Clifton E, Bryden Wayne A, Call Charles J, Hickey Anthony J, et al. Real-Time Investigation of Tuberculosis Transmission: Developing the Respiratory Aerosol Sampling Chamber (RASC). PLoS One 2016;11(1):e0146658. Doi: 10.1371/journal.pone.0146658.

15 Matuka O, Singh TS, Bryce E, Yassi A, Kgasha O, Zungu M, et al. Pilot study 
Published in final edited form as: J Infect. 2017 Sep; 75(3):191-197. doi: 10.1016/j.jinf.2017.06.009

to detect airborne Mycobacterium tuberculosis exposure in a South African

public healthcare facility outpatient clinic. J Hosp Infect 2015;89(3):192-6. Doi:

10.1016/j.jhin.2014.11.013. 


\section{FIGURES}
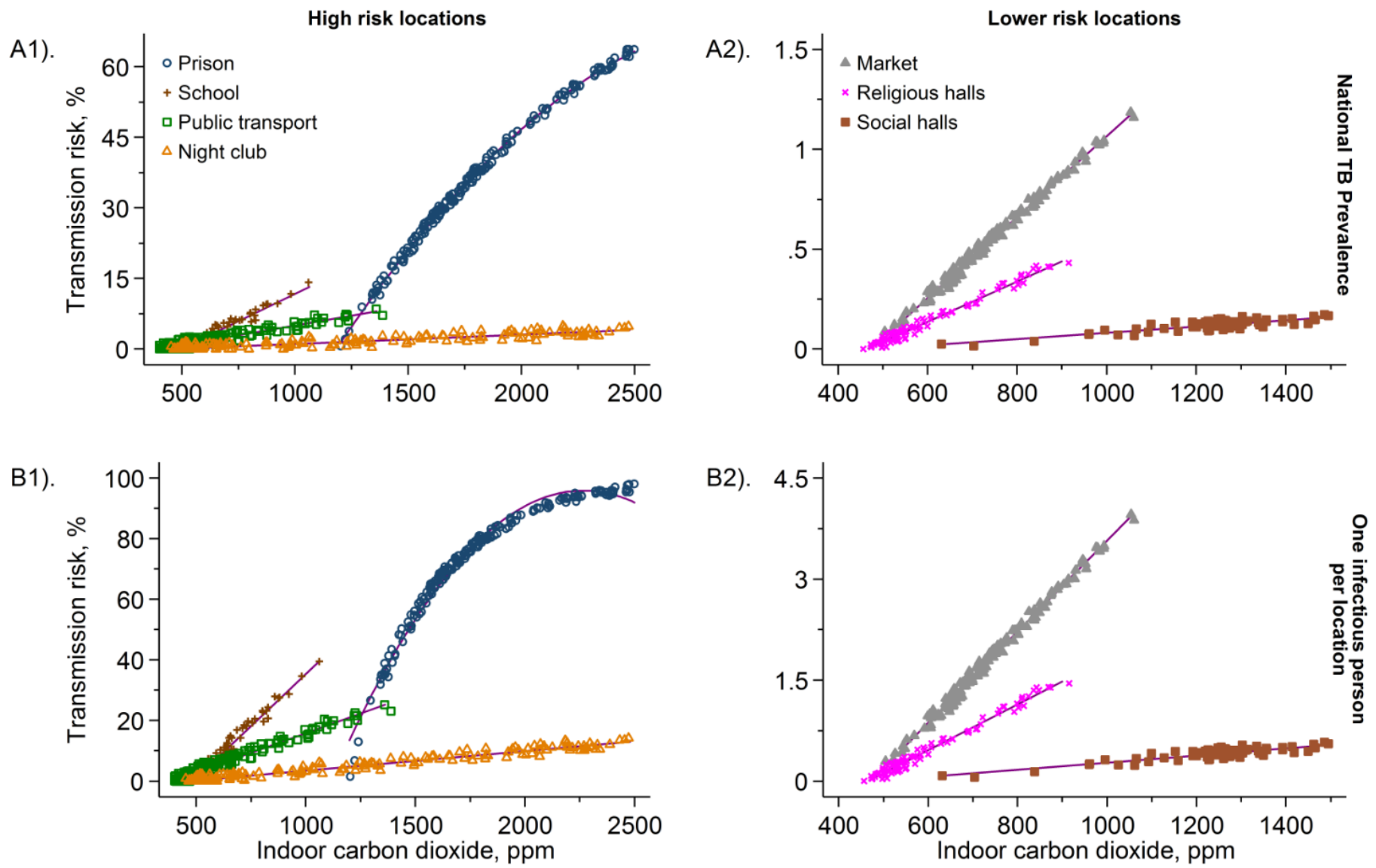

Figure 1. Annual tuberculosis transmission risk at locations of public importance in Dar es Salaam,

Tanzania. Annual tuberculosis transmission risk estimates based on varying environmental $\mathrm{CO}_{2}$ levels (in parts per million, ppm) at higher risk (Panels A1 and B1) and lower risk locations (Panels A2 and B2, different scales), and under the assumption of the national TB prevalence (295 infectious cases/100,000 population, Panels A) and one infectious person at the location (Panels B). Lines indicate fitted risk of transmission. The model is based on quanta generation rate of $1.25 /$ hour from infectious TB patient ${ }^{7}$. The mean outdoor $\mathrm{CO}_{2}$ level at the locations was $431.1 \mathrm{ppm}$. 

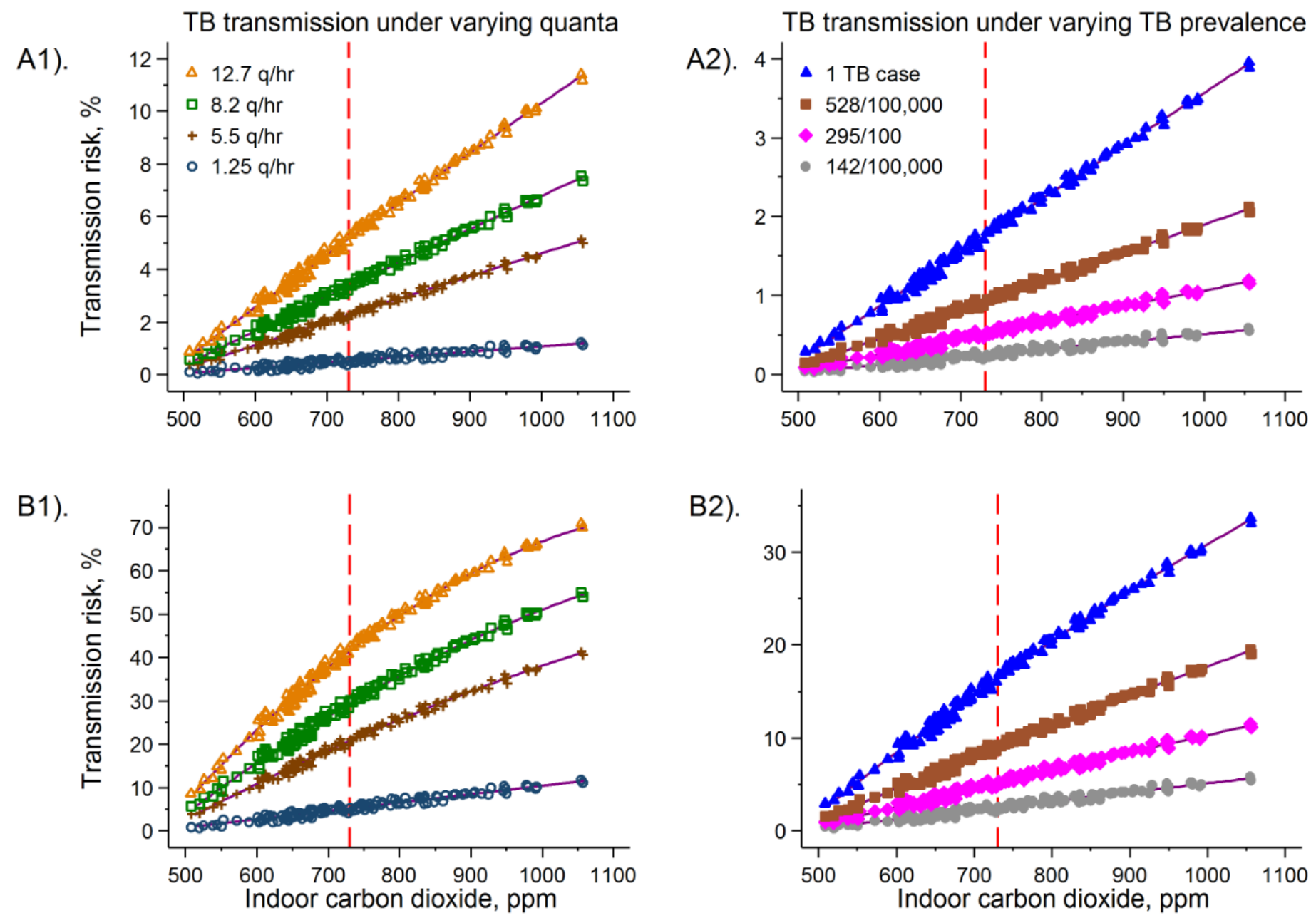

Figure 2. Comparison of TB transmission risks at the largest market in Dar es Salaam. Comparisons of TB transmission risks at a market in Dar es Salaam. Briefly, Panels A1 and A2 show estimates of annual risks of TB transmission at different quanta generation rates and TB prevalence for a customer who visits the market for one hour per week for one year. Panel B1 and B2 show the annual risks of TB transmission for a trader under different quanta generation rates and TB prevalence assuming a trader works 48 hours during each week over a period of 11 months in a year. The red dashed line show the mean $\mathrm{CO}_{2}$ level in the market. 

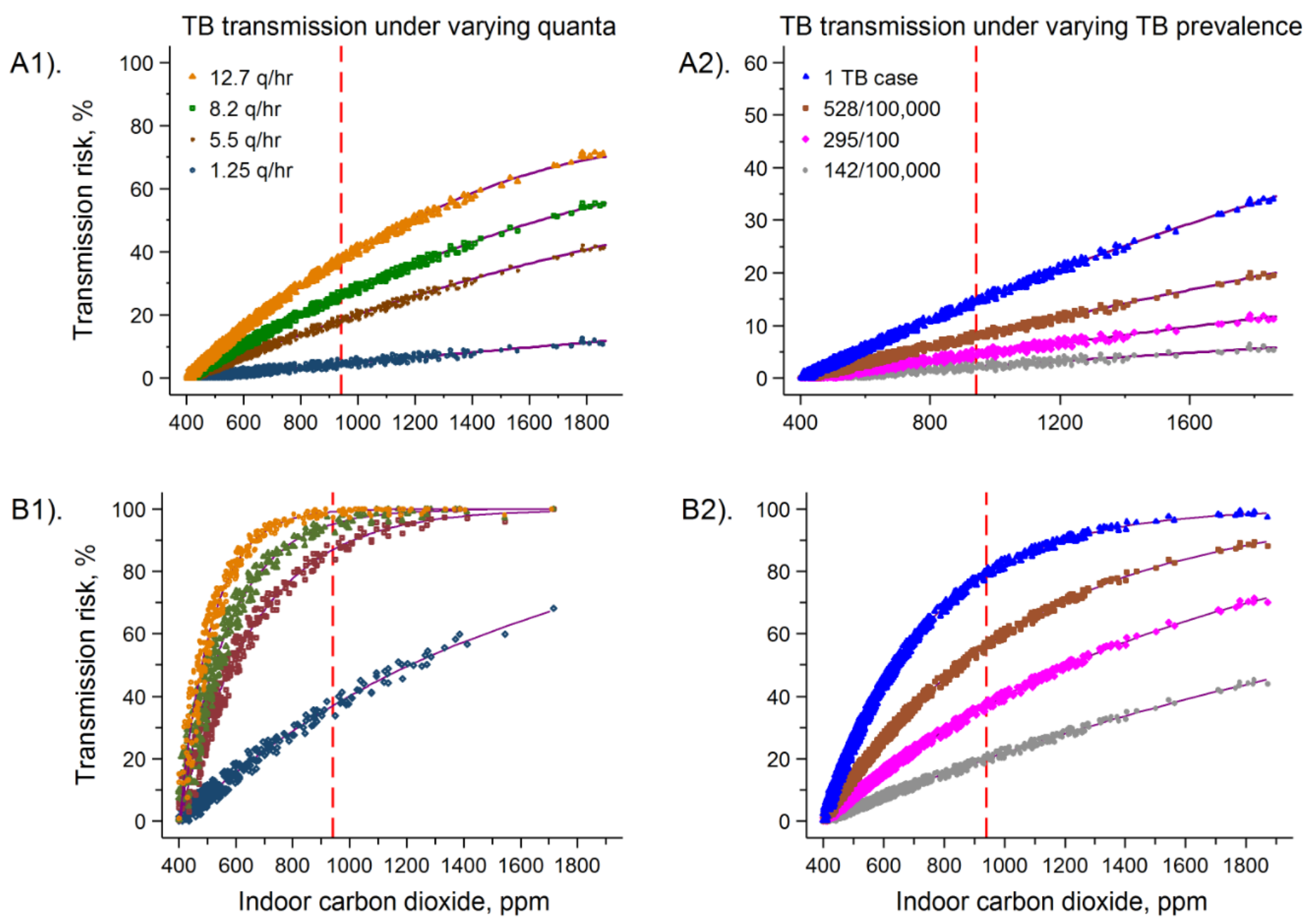

Figure 3. Comparison of TB transmission risks on public transportation in Dar es Salaam. A plot of annual TB transmission risks estimated from the public transport (commuter buses) in Dar es Salaam. Briefly, Panels A1 and A2 show estimates of annual risks of TB transmission under different quanta generation rates and TB prevalence for a passenger commuting on public transport for one year. Panels B1 and B2 show the annual risks of TB transmission for bus drivers and conductors working under different quanta generation rates and TB prevalence. Red dashed line show the mean $\mathrm{CO}_{2}$ levels in the commuter buses. 
Table 1. Carbon dioxide gas $\left(\mathrm{CO}_{2}\right)$ levels recorded at locations of public importance in Dar es Salaam, Tanzania, and the annual tuberculosis (TB) transmission risk estimates based on varying assumptions of type and number of individuals, quanta generation rate, time of exposure and TB prevalence.

\begin{tabular}{|c|c|c|c|c|c|c|c|c|}
\hline \multirow[t]{2}{*}{ Infrastructure } & \multirow{2}{*}{$\begin{array}{l}\text { Type of } \\
\text { individuals at risk }\end{array}$} & \multirow{2}{*}{$\begin{array}{l}\text { Mean } \mathrm{CO}_{2}(\mathrm{SD}) \text {, } \\
\text { ppm }\end{array}$} & \multirow{2}{*}{$\begin{array}{l}\text { Number of } \\
\text { people }\end{array}$} & \multirow{2}{*}{$\begin{array}{l}\text { Quanta, } \\
\text { q/hour }\end{array}$} & \multirow{2}{*}{$\begin{array}{l}\text { Time of exposure } \\
\text { in hours }\end{array}$} & \multirow{2}{*}{$\begin{array}{l}\text { TB prevalence per } \\
100,000 \text { population }\end{array}$} & \multicolumn{2}{|c|}{ Annual transmission risk (\%) } \\
\hline & & & & & & & Mean & $95 \% \mathrm{Cl}$ \\
\hline \multirow{8}{*}{ Market } & \multirow{5}{*}{ Customers } & \multirow{8}{*}{730 (109) } & \multirow{8}{*}{100} & 1.25 & 208 & 295 & 0.49 & $0.48,0.51$ \\
\hline & & & & 1.25 & 208 & 528 & 0.89 & $0.86,0.91$ \\
\hline & & & & 12.70 & 208 & 295 & 4.90 & $4.80,5.10$ \\
\hline & & & & 12.70 & 208 & 528 & 8.60 & $8.40,8.80$ \\
\hline & & & & 1.25 & 1,112 & 295 & 4.91 & $4.77,5.05$ \\
\hline & \multirow{3}{*}{ Traders } & & & 1.25 & 1,112 & 528 & 8.59 & $8.35,8.83$ \\
\hline & & & & 12.70 & 1,112 & 295 & 38.61 & $37.73,39.50$ \\
\hline & & & & 12.70 & 1,112 & 528 & 56.80 & $55.70,57.85$ \\
\hline \multirow{4}{*}{ Prisons } & \multirow{4}{*}{ Prisoners } & \multirow{4}{*}{$1,892(469)$} & \multirow{4}{*}{40} & 1.25 & 3,200 & 295 & 38.40 & $37.60,39.20$ \\
\hline & & & & 1.25 & 3,200 & 528 & 55.50 & $54.60,56.40$ \\
\hline & & & & 12.70 & 3,200 & 295 & 95.20 & $94.80,95.60$ \\
\hline & & & & 12.70 & 3.200 & 528 & 98.60 & $98.40,98.90$ \\
\hline \multirow{4}{*}{ Night clubs } & \multirow{4}{*}{ Club attendees } & \multirow{4}{*}{$1,488(787)$} & \multirow{4}{*}{100} & 1.25 & 208 & 295 & 1.95 & $1.87,2.03$ \\
\hline & & & & 1.25 & 208 & 528 & 3.45 & $3.31,3.60$ \\
\hline & & & & 12.70 & 208 & 295 & 17.20 & $16.50,17.90$ \\
\hline & & & & 12.70 & 208 & 528 & 27.43 & $26.40,28.40$ \\
\hline \multirow{8}{*}{$\begin{array}{l}\text { Public } \\
\text { transportation }\end{array}$} & \multirow{5}{*}{ Passengers } & \multirow{8}{*}{$941(246)$} & \multirow{5}{*}{30} & 1.25 & 264 & 295 & 2.36 & $2.33,2.39$ \\
\hline & & & & 1.25 & 264 & 528 & 4.16 & $4.11,4.22$ \\
\hline & & & & 12.70 & 264 & 295 & 20.56 & $20.30,20.8$ \\
\hline & & & & 12.70 & 264 & 528 & 32.65 & $32.31,32.99$ \\
\hline & & & & 1.25 & 2,640 & 295 & 20.29 & $20.04,20.53$ \\
\hline & \multirow{3}{*}{ Drivers } & & \multirow{3}{*}{30} & 1.25 & 2,640 & 528 & 32.27 & $31.93,32.61$ \\
\hline & & & & 12.70 & 2,640 & 295 & 80.63 & $80.25,81.01$ \\
\hline & & & & 12.70 & 2,640 & 528 & 91.24 & $90.96,91.51$ \\
\hline Religious halls & Attendees & 629.31 (105) & 100 & 1.25 & 104 & 295 & 0.13 & $0.12,0.14$ \\
\hline
\end{tabular}


Published in final edited form as: J Infect. 2017 Sep; 75(3):191-197. doi: 10.1016/j.jinf.2017.06.009

\begin{tabular}{|c|c|c|c|c|c|c|c|c|}
\hline \multirow{7}{*}{ Social halls } & \multirow{7}{*}{ Attendees } & \multirow{7}{*}{$1,262.9$ (149) } & \multirow{7}{*}{200} & 1.25 & 104 & 528 & 0.23 & $0.21,0.25$ \\
\hline & & & & 12.70 & 104 & 295 & 1.30 & $1.20,1.40$ \\
\hline & & & & 12.70 & 104 & 528 & 2.30 & $2.12,2.48$ \\
\hline & & & & 1.25 & 32 & 295 & 0.12 & $0.118,0.125$ \\
\hline & & & & 1.25 & 32 & 528 & 0.22 & $0.21,0.223$ \\
\hline & & & & 12.70 & 32 & 295 & 1.23 & $1.20,1.26$ \\
\hline & & & & 12.70 & 32 & 528 & 2.19 & $2.13,2.24$ \\
\hline \multirow{4}{*}{ Schools } & \multirow{4}{*}{ Students } & \multirow{4}{*}{$655(230)$} & \multirow{4}{*}{50} & 1.25 & 1,280 & 295 & 4.02 & $3.95,4.09$ \\
\hline & & & & 1.25 & 1,280 & 528 & 7.03 & $6.91,7.14$ \\
\hline & & & & 12.70 & 1,280 & 295 & 32.30 & $31.95,32.66$ \\
\hline & & & & 12.70 & 1,280 & 528 & 48.78 & $48.34,49.23$ \\
\hline
\end{tabular}

Abbreviations: $\mathrm{CO}_{2}$, carbon dioxide gas; $95 \% \mathrm{Cl}, 95 \%$ confidence interval; SD, standard deviation; ppm, parts per million; TB, tuberculosis 